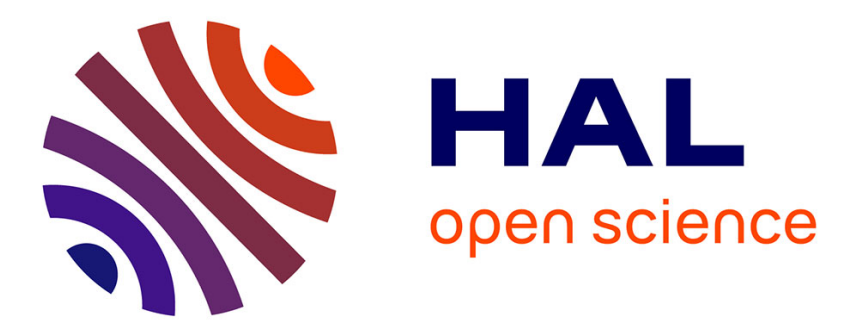

\title{
Pyridine-Based PCP-Ruthenium Complexes: Unusual Structures and Metal-Ligand Cooperation
}

Niklas von Wolff, Shan Tang, Yael Diskin-Posner, Gregory Leitus, Yehoshoa Ben-David, David Milstein

\section{- To cite this version:}

Niklas von Wolff, Shan Tang, Yael Diskin-Posner, Gregory Leitus, Yehoshoa Ben-David, et al.. Pyridine-Based PCP-Ruthenium Complexes: Unusual Structures and Metal-Ligand Cooperation. Journal of the American Chemical Society, 2019, 141 (18), pp.7554-7561. 10.1021/jacs.9b02669 . hal-03008807

\section{HAL Id: hal-03008807 https://hal.science/hal-03008807}

Submitted on 16 Nov 2020

HAL is a multi-disciplinary open access archive for the deposit and dissemination of scientific research documents, whether they are published or not. The documents may come from teaching and research institutions in France or abroad, or from public or private research centers.
L'archive ouverte pluridisciplinaire HAL, est destinée au dépôt et à la diffusion de documents scientifiques de niveau recherche, publiés ou non, émanant des établissements d'enseignement et de recherche français ou étrangers, des laboratoires publics ou privés. 


\title{
Pyridine-based PCP-Ruthenium Complexes: Unusual Structures and Metal-Ligand Cooperation
}

\author{
Shan Tang, ${ }^{\dagger \S}$ Niklas von Wolff, ${ }^{\dagger}$ Y Yael Diskin-Posner, ${ }^{\ddagger}$ Gregory Leitus, ${ }^{\dagger}$ Yehoshoa Ben-David, ${ }^{\dagger}$ David \\ Milstein ${ }^{\dagger *}$
}

'Department of Organic Chemistry and ${ }^{\ddagger}$ Chemical Research Support, the Weizmann Institute of Science, Rehovot 76100, Israel

\begin{abstract}
Metal-ligand cooperation (MLC) by dearomatization/aromatization provides a unique way for bond activation, which has led to the discovery of various acceptorless dehydrogenative coupling reactions. However, most of the studies are based on pincer complexes with a central nitrogen donor. Aiming at exploration of the possibility of MLC by PCP-type pincer complexes, we report herein the synthesis, characterization, structure and reactivity of pyridine-based PCP-Ru complexes. X-ray structures and DFT calculations indicate a carbenoid character of quaternized pyridine-based PCP-Ru complexes. These complexes undergo dearomatization by direct deprotonation, and the dearomatized complex can react with hydrogen, alcohols or nitriles to regain aromatization via MLC.
\end{abstract}

\section{INTRODUCTION}

Developing new approaches for bond activation plays a key role in the discovery of novel catalytic reactions. Over the past decades, metal complexes with non-innocent ligands, which can cooperate with the metal center during substrate activation, have demonstrated unique catalytic reactivity in the activation of inert chemical bonds. ${ }^{1-3}$ Pincer complexes are a class of metal complexes containing tridentate ligands with meridional geometry. ${ }^{4-5}$ Besides the importance in organometallic chemistry, the possibilities of structure and electronic modifications of pincer ligands have provided opportunities for developing highly efficient and selective catalysts in organic synthesis. ${ }^{6-9}$ Arene-based PCP pincer complexes and pyridine-based PNP pincer complexes are among the most common pincer complexes in organometallic chemistry.

Since 2005, our group has studied the metal-ligand cooperation (MLC) of pyridine-based PNP/PNN pincer complexes via dearomatization/aromatization of the pincer ligand (Scheme 1a). ${ }^{10}$ Pyridine-based pincer complexes can be deprotonated by base at the benzylic carbon, resulting in dearomatization of the pyridine ring. ${ }^{11-13}$ Cooperation between the ligand and the metal center of the dearomatized complex can result in the activation of chemical bonds (H-H, O-H, N-H, C-H etc.) with consequent aromatization. The process can be reversible, resulting in product formation. This bond activation approach has led to the discovery of a series of unprecedented, highly efficient and environmentally friendly dehydrogenative coupling reactions of alcohols with hydrogen evolution. ${ }^{10,14-15}$ It is noteworthy that the formal oxidation state of the central metal remains unchanged during the whole reaction process. ${ }^{16-21} \mathrm{We}$ set out to explore whether this MLC approach could be expanded to PCP-type complexes, and what effects it would have on the structure and reactivity of such complexes.

Scheme 1. Metal-Ligand Cooperation (MLC) of Pyridinebased Pincer Complexes via Dearomatization / Aromatization.

(a) PNP complexes

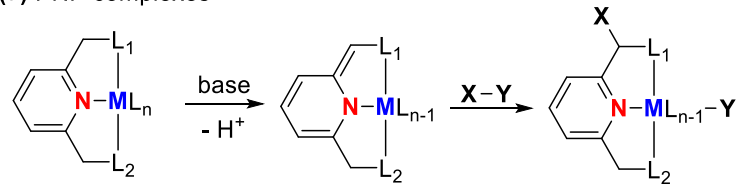

(b) Envisioned MLC based on PCP complexes

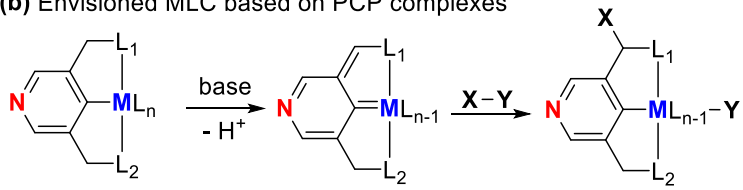

Besides the dearomatization of pyridine-based PNP/PNN pincer complexes, our group also reported on the dearomatization of hydroquinone PCP-type pincer complexes by deprotonation or oxidation. ${ }^{22-23}$ More recently, Ozerov and co-workers reported on the dearomatization of a high-valent benzene-based PCP-Re(V) complex by deprotonation. ${ }^{24} \mathrm{We}$ are unaware of other reports on dearomatization of PCP pincer complexes. Although the methylene group at the meta position of pyridine has a somewhat higher $\mathrm{pKa}$ value compared to the methylene group at the ortho position of pyridine, ${ }^{25}$ we envisioned that $3,5-$ lutidine-based pincer complexes might also undergo similar dearomatization/aromatization as 2,6-lutidine-based pincer complexes (Scheme 1b). Due to the increased trans effect of the carbon metal moiety (as compared to nitrogen donors), new re- 
activity and catalysis are expected. In particular, the dearomatization of the pyridine-based PCP ligand might involve the formation of metal carbene species with the potential of unique reactivity in catalytic acceptorless dehydrogenation reactions. Herein, we report the synthesis, unique structures, and reactivity of pyridine- and pyridinium - based PCP-Ru complexes, including metal-ligand coorperation based on dearomatization/aromatization.

\section{RESULTS AND DISCUSSION}

In 2004, we reported the synthesis and characterization of pyridine-based PCP-Pd/Rh complexes. ${ }^{26}$ Nevertheless, deprotonation and possible dearomatization of these complexes were not explored at that time. In this work, two 3,5-lutidine-based bisphosphine ligands (1a and 1b) were synthesized from 3,5pyridinedicarboxylic acid (See Supporting Information for detailed procedure). Reaction of $\mathbf{1 a}$ or $\mathbf{1 b}$ with $\left[\mathrm{RuCl}_{2}(\mathrm{COD})\right]_{\mathrm{n}}$ in ethanol at $120^{\circ} \mathrm{C}$ for $48 \mathrm{~h}$ resulted in the formation of a yellow precipitate. After cooling to room temperature, the precipitate was collected and dissolved in pyridine upon heating at $120^{\circ} \mathrm{C}$ for $30 \mathrm{~min}$. The pyridine solution was then reacted with $\mathrm{CO}$ (1 atm) at room temperature for $24 \mathrm{~h}$. The reaction with $1 \mathrm{a}$ afforded $2 \mathrm{a}$ as a pale yellow solid in $76 \%$ yield while the reaction with $\mathbf{1 b}$ furnished $\mathbf{2 b}$ as a yellow solid in $70 \%$ yield (Scheme 2). The ${ }^{31} \mathrm{P}\left\{{ }^{1} \mathrm{H}\right\}$ NMR spectra of $\mathbf{2} \mathbf{a}$ and $\mathbf{2} \mathbf{b}$ showed characteristic singlets at 74.53 and $91.12 \mathrm{ppm}$, respectively. The IR spectra of $\mathbf{2} \mathbf{a}$ and $\mathbf{2 b}$ exhibited in each case two strong absorptions bands of the CO ligands with relative absorbance of $1: 1$, indicative of a $90^{\circ}$ angle between the two $\mathrm{CO}$ ligands in the generated pyridine-based PCP-Ru complexes. In the ${ }^{13} \mathrm{C}\left\{{ }^{1} \mathrm{H}\right\}$ NMR spectra, the ipso-carbons of $\mathbf{2} \mathbf{a}$ and $\mathbf{2} \mathbf{b}$ gave rise to singlets at 181.11 and $182.49 \mathrm{ppm}$, respectively.

\section{Scheme 2. Synthesis of Pyridine-based PCP-Ru Complexes}
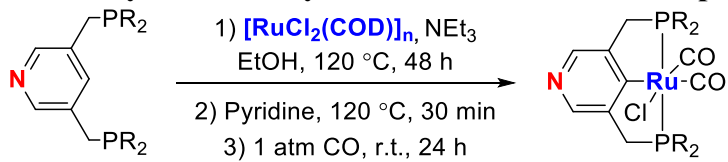

1a: $\mathrm{R}={ }^{i} \mathrm{Pr}$

3) $1 \mathrm{~atm} \mathrm{CO}$, r.t., $24 \mathrm{~h}$

2a: $\mathrm{R}={ }^{i} \mathrm{Pr}, 76 \%$

1b: $\mathrm{R}={ }^{t} \mathrm{Bu}$

2b: $\mathrm{R}={ }^{t} \mathrm{Bu}, 70 \%$

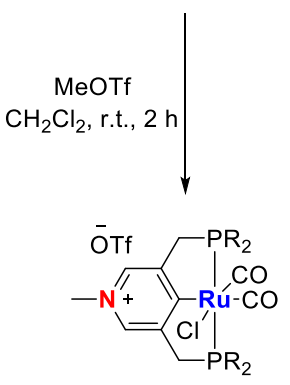

3a: $\mathrm{R}={ }^{i} \mathrm{Pr}$, quant.

3b: $R={ }^{t} \mathrm{Bu}$, quant.

Single crystals of $\mathbf{2} \mathbf{a}$ and $\mathbf{2} \mathbf{b}$ were obtained by solvent evaporation of their pyridine solutions under vacuum, exhibiting octahedral configurations with mutually cis CO ligands (Figure 1). The $\mathrm{Ru}-\mathrm{Cl}$ bond distances of $\mathbf{2} \mathbf{a}$ and $\mathbf{2} \mathbf{b}$ are quite similar, while the ipso $\mathrm{Ru}-\mathrm{C}$ bond distances in $\mathbf{2 a}$ and $\mathbf{2 b}(2.1059(15) \AA$ and 2.082(2) $\AA$, respectively) are slightly different. They are both significantly longer than the $\mathrm{Ru}-\mathrm{C}$ bond in a similar benzenebased PCP-Ru complex (1.896(4) $\AA$ ) reported by our group, ${ }^{27}$ demonstrating the significant electronic effect of the nitrogen atom in the lutidine backbone. The P-Ru-P bond angles of $\mathbf{2 a}$ and $\mathbf{2 b}$ are both smaller than $180^{\circ}\left(\left(157.623(14)^{\circ}\right)\right.$ and $158.15(2)^{\circ}$, respectively).

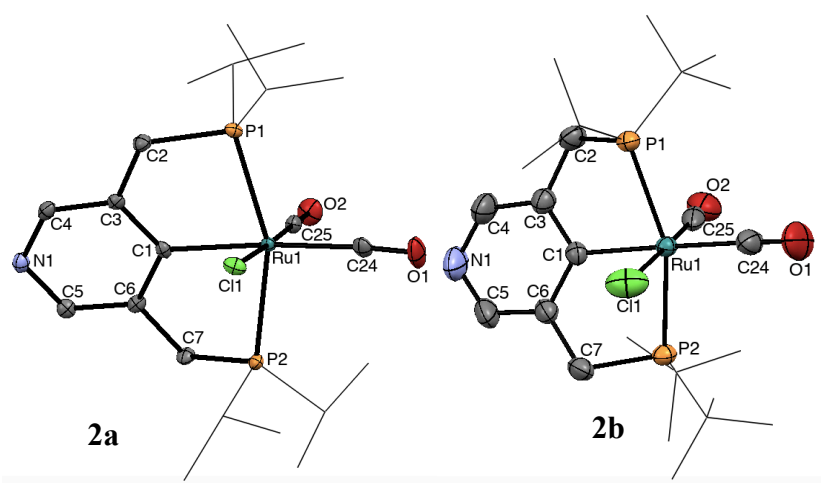

Figure 1. X-ray crystal structures of $\mathbf{2 a}$ and $\mathbf{2 b}$ (thermal ellipsoids set at $50 \%$ probability level, $i$-propyl and $t$-butyl groups are presented as wireframe, and hydrogen atoms are omitted for clarity). Selected bond distances $(\AA)$ and angles $\left({ }^{\circ}\right)$ for 2a: Ru1-C1 2.106(2), Ru1-C24 1.949(2), Ru1-C25 1.850(2), Ru1-Cl1 2.4589(6), Ru1-P1 2.3787(6), Ru1-P2 2.3840(7), C3-C2 1.510(3), C6-C7 1.510(3), C1-C3 1.403(3), C1-C6 1.400(3), C3-C4 1.391(3), C5-C6 1.392(3), P1-Ru1-P2 157.62(2), C1-Ru1-C11 87.33(6), C1-Ru1-C24 172.58(10), C24-Ru1C25 93.9(1); 2b: Ru1-C1 2.082(2), Ru1-C24 1.960(3), Ru1-C25 1.983(4), Ru1-Cl1 2.446(1), Ru1-P1 2.4408(6), Ru1-P2 2.4332(6), C2C3 1.505(4), C6-C7 1.508(4), C1-C3 1.400(3), C1-C6 1.409(3), C3-C4 1.387(4), C5-C6 1.387(4), P1-Ru1-P2 158.15(2), C1-Ru1-Cl1 88.00(7), C1-Ru1-C24 177.1(1), C24-Ru1-C25 94.3(1).

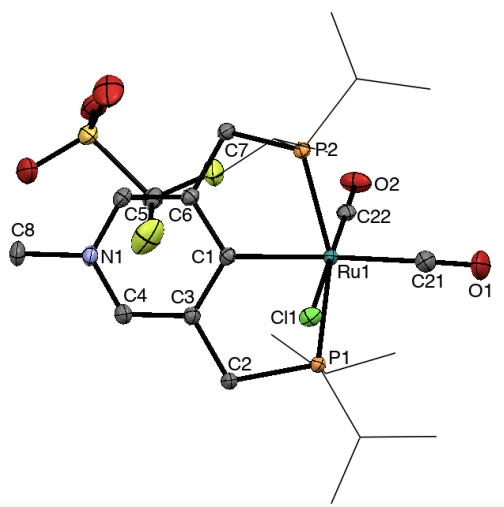

Figure 2. X-ray crystal structure of 3a (thermal ellipsoids set at $50 \%$ probability level, isopropyl groups are presented as wireframe, and hydrogen atoms are omitted for clarity). Selected bond distances $(\AA)$ and angles $\left(^{\circ}\right)$ for 3a: Ru1-C1 2.095(1), Ru1-C21 1.953(2), Ru1-C22 1.851(3), Ru1-Cl1 2.4530(6), Ru1-P1 2.3832(4), Ru1-P2 2.3791(4), C2-C3 1.505(2), C6-C7 1.508(2), C1-C3 1.410(2), C1-C6 1.409(2), C5-C6 1.376(2), C3-C4 1.387(2), N1-C8 1.479(2), P1-Ru1-P2 159.80(1), C1-Ru1-Cl1 89.27(4), C1-Ru1-C21 175.80(6), C21-Ru1C22 93.15(7).

As was observed in our previous report, ${ }^{26}$ the free pyridine nitrogen atoms in pyridine-based pincer complexes might further bind to other metal centers to form coordination polymers. In order to avoid this possibility, and also to enhance the acidity of the benzylic position, we sought to quaternize $\mathbf{2 a}$ and $\mathbf{2 b}$. Mixing a stoichiometric amount of methyl triflate with these complexes in dichloromethane at room termperature, ${ }^{28}$ the quaternized pyridine-based PCP-Ru complexes were obtained in quantitative yields (Scheme 2, 3a and $\mathbf{3 b}$ ). Only slight chemical shifts of the peaks in the ${ }^{31} \mathrm{P}\left\{{ }^{1} \mathrm{H}\right\}$ NMR spectra of these 
complexes as compared with $\mathbf{2 a}$ and $\mathbf{2 b}$ were observed. However, the ${ }^{13} \mathrm{C}\left\{{ }^{1} \mathrm{H}\right\}$ NMR spectrum of $\mathbf{3 a}$ and $\mathbf{3} \mathbf{b}$ showed significant changes in the chemical shifts of the ipso-carbons, from 181.11 to $206.41 \mathrm{ppm}$ (3a) and from 182.49 to $207.96 \mathrm{ppm}$ (3b). These results might be rationalized by the strong electron-withdrawing effect of the quaternized pyridine nitrogen, resulting in electronic deshielding of the ipso-carbons. X-ray quality crystals of 3a were obtained by slow evaporation of its benzene solution (Figure 2). Noteworthily, the bond distance of ipso $\mathrm{C}-\mathrm{Ru}$ in 3a $(2.0948(13) \AA)$, is shorter than that of 2a $(2.1059(15) \AA)$. Moreover, in 3a the $\mathrm{C} 3-\mathrm{C} 4$ and $\mathrm{C} 5-\mathrm{C} 6$ bonds (about $1.38 \AA$ ) differ significantly from the $\mathrm{C} 1-\mathrm{C} 3$ and $\mathrm{C} 1-\mathrm{C} 6$ bonds (about $1.41 \AA$ ), as opposed to that in $\mathbf{2 a}(1.39-1.40 \AA)$. An outer-sphere triflate counter anion was also determined in the crystal structure.

(a) NBO representation of bonding situation

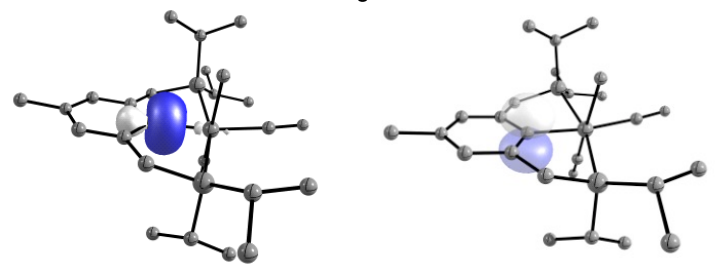

$\mathrm{sp}^{2}$-type lone pair on ipso-carbon vacant $p$-type orbital on ipso-carbon

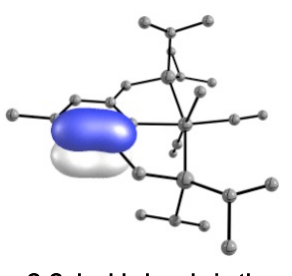

C-C double bonds in the "Dewar pyridinium" ring

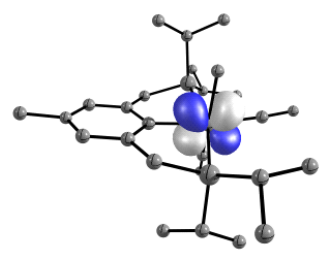

d-type lone pair on ruthenium (b) 'Best' Lewis description
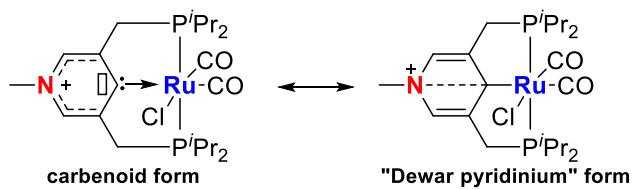

Figure 3. Calculated bonding picture of 3a.

In order to understand the bonding pattern in 3a more precisely, we performed DFT calculations (see SI for details) and NBO analysis. Calculated bond lengths fit well with the experimental values. Interestingly, the observed bond lengths within the aromatic core upon quaternization of $\mathbf{2 a}$ show dissymmetry and are not well explained by the canonical Lewis structure depicted in Scheme 2. Also, the shortening of the $\mathrm{Ru}-\mathrm{C}$ bond from $2.106(2) \AA$ in $\mathbf{2 a}$ to $2.095(1) \AA$ in $\mathbf{3 a}$ is difficult to rationalize using the classical bonding picture in Scheme 2. Instead, NBO analysis suggests a partial carbenoid character of the ipso-carbon in 3a (Figure 3). The carbenoid lone pair (Figure $3 \mathrm{a}, 1^{\text {st }}$ $\mathrm{NBO}$ ) is involved in $3 \mathrm{c} 4 \mathrm{e}$ bonding with the adjacent $\mathrm{Ru}-\mathrm{CO}$ bond. Nevertheless, the carbenoid character is strongly attenuated by donation of electron density into the vacant orbital on carbon from the adjacent double bonds (Figure $3 \mathrm{a}, 2^{\text {nd }}$ and $3^{\text {rd }}$ NBO) with only little backdonation from ruthenium-centered orbitals (Figure $3 \mathrm{a}, 4^{\text {th }} \mathrm{NBO}$ ) explaining the relatively long Ru$\mathrm{C}$ bond distance. Another way of thinking about bonding in $\mathbf{3 a}$ would be a formal "Dewar-pyridinium"-Lewis structure (Figure $3 \mathrm{~b}$, right), which allows us to rationalize the short $\mathrm{C} 3-\mathrm{C} 4$ and
C5-C6 bond lengths with longer $\mathrm{C} 1-\mathrm{C} 3$ and $\mathrm{C} 1-\mathrm{C} 6$ distances and contraction of the N1-C1 bond length from $2.830 \AA$ in $\mathbf{2 a}$ to $2.778 \AA$ in $\mathbf{3 a}$.

Following characterization of the pyridine-based PCP-Ru complexes, we tried to deprotonate them with an equimolar amount of base such as $\mathrm{KO}^{t} \mathrm{Bu}$ or KHMDS. Mixing 3a with $\mathrm{KO}^{t} \mathrm{Bu}$ in dioxane resulted in a dark purple solution. After workup, dearomatized complex $\mathbf{4 a}$ was isolated in $70 \%$ yield (Scheme 3). Similar results were observed when KHMDS was used instead of $\mathrm{KO}^{t} \mathrm{Bu}$. The ${ }^{31} \mathrm{P}\left\{{ }^{1} \mathrm{H}\right\}$ NMR spectrum showed a clear $\mathrm{AB}$ system at $72.03 \mathrm{ppm}$ and $63.64 \mathrm{ppm}$ with a coupling constant of ${ }^{2} J_{\mathrm{PP}}=239.0 \mathrm{~Hz}$, indicating non-equivalent phosphorus nuclei coordinated to the metal center. The non-equivalent two protons of the pyridine ring gave rise to peaks at $5.60 \mathrm{ppm}$ and $5.32 \mathrm{ppm}$ in the ${ }^{1} \mathrm{H}$ NMR spectrum. The vinylic proton at the deprotonated benzylic position exhibited a low-field shift to $3.60 \mathrm{ppm}$, showing a dd resonance $\left({ }^{2} J_{\mathrm{HP}}=5.5 \mathrm{~Hz},{ }^{4} J_{\mathrm{HP}}=3.8\right.$ $\mathrm{Hz}$ ). In the ${ }^{13} \mathrm{C}\left\{{ }^{1} \mathrm{H}\right\}$ NMR spectrum, the deprotonated benzylic carbon was observed at $65.78 \mathrm{ppm}$ with strong C-P coupling $\left({ }^{1} J_{\mathrm{CP}}=67.2 \mathrm{~Hz}\right)$. The ipso-carbon of the dearomatized pyridinebased PCP-Ru complex exhibited an up-field chemical shift to $180.59 \mathrm{ppm}$. The IR absorption of two CO ligands exhibit bands at $2012 \mathrm{~cm}^{-1}$ and $1943 \mathrm{~cm}^{-1}$ in a ratio of $1: 1$, indicating that the two CO ligands still maintain an angle of $90^{\circ}$ in the dearomatized complex.

\section{Scheme 3. Dearomatization of 3a by Deprotonation}
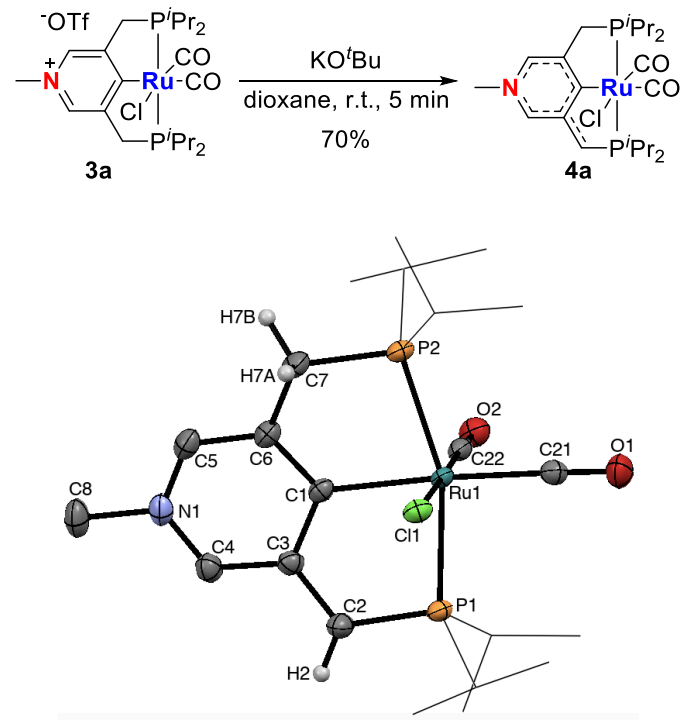

Figure 4. X-ray crystal structure of $\mathbf{4 a}$ (thermal ellipsoids set at $50 \%$ probability level, isopropyl groups are presented as wireframe, and hydrogen atoms are white spheres except for the side arm are omitted for clarity). Selected bond distances $(\AA)$ and angles $\left({ }^{\circ}\right)$ for $\mathbf{4 a}$ : Ru1-C1 2.106(2), Ru1-C21 1.949(2), Ru1-C22 1.859(2), Ru1-C11 2.4751(6), Ru1-P1 2.3871(6), Ru1-P2 2.3769(5), C2-C3 1.399(3), C6-C7 1.504(3), C1-C3 1.440(3), C1-C6 1.339(3), C3-C4 1.421(3), C5-C6 1.406(3), N1-C8 1.478(3), P1-Ru1-P2 161.23(3), C1-Ru1-Cl1 85.64(6), C1Ru1-C21 175.08(8), C21-Ru1-C22 89.9(1).

X-ray quality crystals of $4 \mathbf{a}$ were obtained by layering its dioxane/benzene solution with pentane (Figure 4), exhibiting an octahedral complex bearing a bound chloride and two mutually cis CO ligands. The ipso Ru-C bond distance in 4a of 2.106(2) $\AA$ is similar to that of 2a. As expected, the $\mathrm{C}-\mathrm{C}$ bond of the deprotonated side $\operatorname{arm}(1.399(3) \AA)$ is significantly shorter than that of the non-deprotonated side arm (1.504(3) $\AA$ ), indicating 
partial double bond character, in conjugation with the pyridine ring. Importantly, a carbenoid resonance structure (which would imply a formal 20 electron species) can be excluded due to the 6-coordinate nature of $\mathbf{4 a}$. NBO calculations on $\mathbf{4 a}$ indeed confirmed the absence of carbenoid character at the ipso-position (Figure 5a). Instead, 4 a might be best described in terms of Lewis structure by the resonance form on the right-hand side of Figure $5 \mathrm{~b}$. The partially occupied lone pair in the meta-position is highly delocalized into the adjacent double bond antibonds (Figure 5b, left). Again, the ipso-C-Ru bond can be described as a $3 \mathrm{c} 4 \mathrm{e}$ interaction between a $\mathrm{sp}^{2}$-type lone pair on carbon donating into the adjacent $\mathrm{Ru}-\mathrm{CO}$ antibond (Figure $5 \mathrm{~b}$, right). Given the absence of carbenoid character, low lying empty orbitals on the ipso-carbon are lacking, limiting the possibility of backbonding from ruthenium and explaining the elongated $\mathrm{Ru}-$ C bond of 2.106(2) $\AA$ in 4a compared to 3a (2.082(2) $\AA$ ).

(a) NBO representation of bonding situation
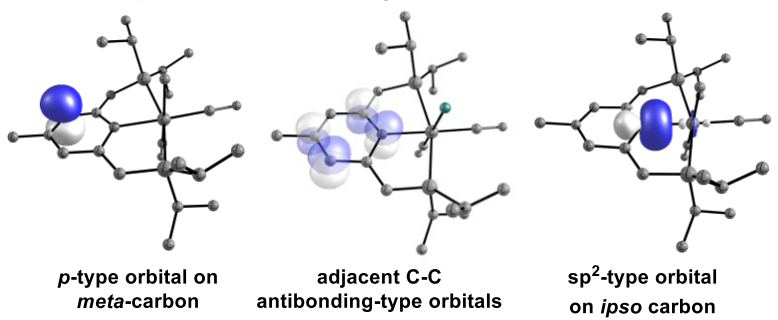

(b) Proposed resonance structures

$$
\text { "best" }
$$

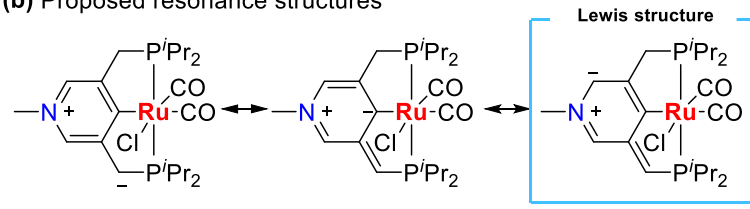

Figure 5. Calculated bonding picture of $\mathbf{4 a}$.
To gain a preliminary insight into the reactivity of the dearomatized complex, we explored the reaction of $\mathbf{4 a}$ with dihydrogen (Scheme 4a). Exposure of a benzene solution of $4 \mathbf{a}$ to $1 \mathrm{~atm} \mathrm{H}_{2}$ led to an instantaneous color change from dark blue to yellow. Full conversion to the ruthenium hydride complex 5a was achieved by heating the solution at $80{ }^{\circ} \mathrm{C}$ for $3 \mathrm{~h}$. The ${ }^{31} \mathrm{P}\left\{{ }^{1} \mathrm{H}\right\}$ NMR spectrum of $\mathbf{5 a}$ showed a characteristic singlet at $87.96 \mathrm{ppm}$, indicating the formation of two equivalent phosphine groups. The ruthenium hydride exhibited a clear triplet in the ${ }^{1} \mathrm{H}$ NMR spectrum at $-7.55 \mathrm{ppm}$ while the pyridine ring protons were found at $8.12 \mathrm{ppm}$. In the ${ }^{13} \mathrm{C}\left\{{ }^{1} \mathrm{H}\right\}$ NMR spectrum, the ipso-carbon shifted downfield from $180.59 \mathrm{ppm}$ to 208.53 ppm. The mechanism of dihydrogen addition to the dearomatized complex $4 \mathbf{a}$ was examined by DFT calculations (Scheme $4 \mathrm{~b}$, see SI for details). The aromatized species $\mathbf{4 a}$ is fully saturated at ruthenium and a first step might thus be the generation of a pentacoordinate species. We hence investigated the energetics of four different mechanistic proposals:(1) loss of CO, (2) a concerted $\mathrm{S}_{\mathrm{N}} 2 @ \mathrm{Ru}$ mechanism, where $\mathrm{H}_{2}$ replaces the chloride ligand, (3) Loss of the chloride ligand, (4) opening of either of the phosphine side-arms. Both pathways (3) and (4) can be excluded due to higher reaction barriers $\left(>36.3 \mathrm{kcal}_{\mathrm{mol}}{ }^{-1}\right.$, see $\mathrm{SI}$ for details), as well as an activation across the $\mathrm{Ru}-\mathrm{C}$ bond ( $>34.1 \mathrm{kcal}^{\mathrm{mol}}{ }^{-1}$, see SI for details). On the other hand, loss of a CO-ligand from 4a might be feasible. Indeed, although the generation of the pentacoordinate species I is $13.3 \mathrm{kcal}^{\mathrm{mol}} \mathbf{m}^{-1}$ higher than the starting material, it allows for the addition and splitting of $\mathrm{H}_{2}$ (TS1, $32.0 \mathrm{kcal}^{\mathrm{mol}} \mathrm{mol}^{-1}$ ) to generate hydride $\mathbf{5 a}$. Pathway (2) is only slightly higher in energy (TS2, 33.0 kcal.mol ${ }^{-1}$ ) and can thus not be ruled out. Here, $\mathrm{H}_{2}$ undergoes a nucleophilic substitution at ruthenium in a highly concerted manner, being directly deprotonated by the leaving chloride ligand. Reprotonation by $\mathrm{HCl}$ then leads to the formation of $\mathbf{5 a}$.

\section{Scheme 4. Aromatization of 4 a upon $\mathrm{H}_{2}$ Addition}

(a) $\mathrm{H}_{2}$ activation by dearomatized complex $4 \mathrm{a}$
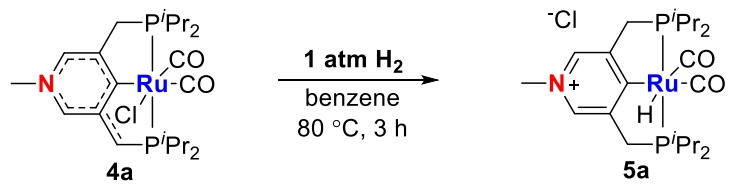

(b) Free energy pathway for $\mathrm{H}_{2}$ activation by 4a

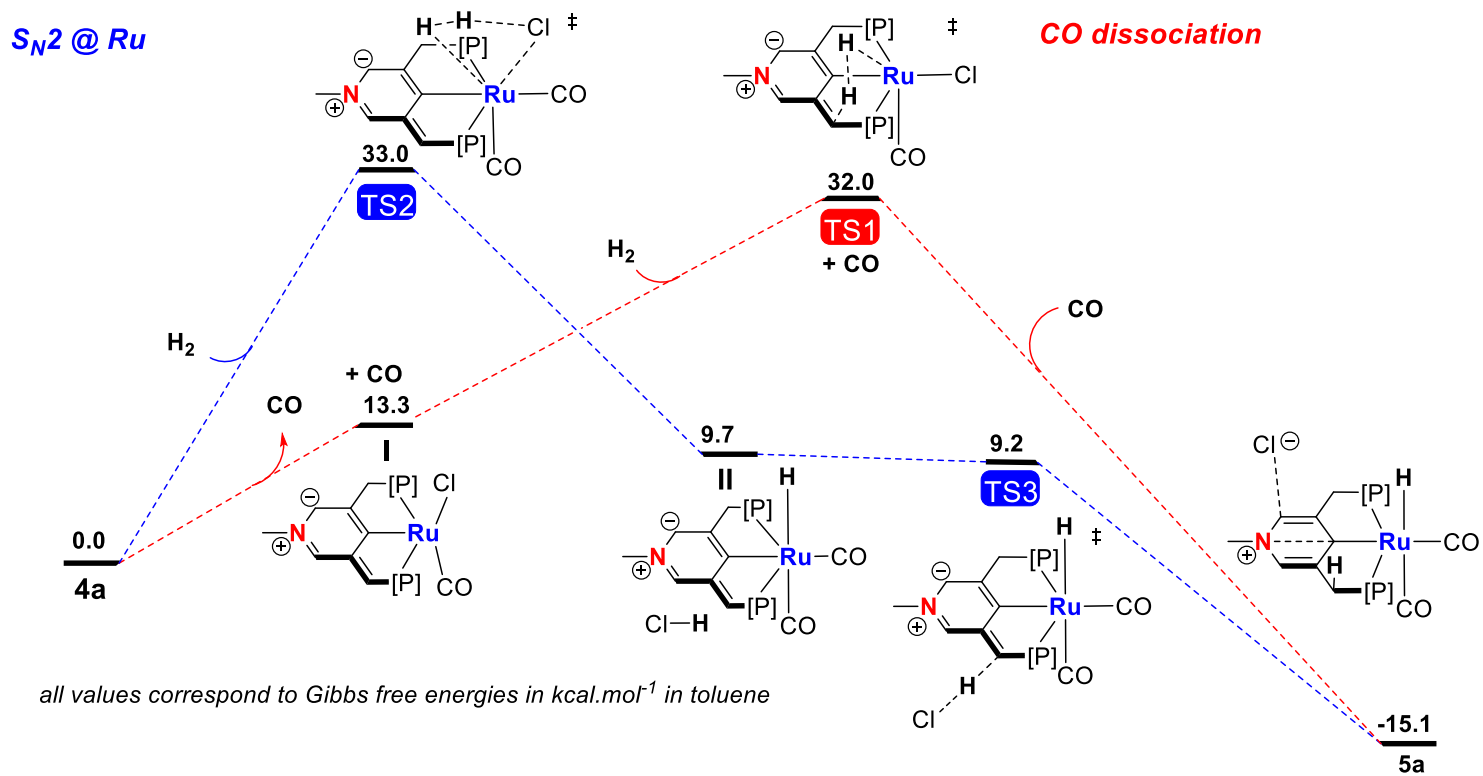


The dearomatization of $\mathbf{2} \mathbf{a}, \mathbf{2} \mathbf{b}$ and $\mathbf{3} \mathbf{b}$ by deprotonation was also explored. Some color change was observed upon addition of $\mathrm{KO}^{t} \mathrm{Bu}$ or $\mathrm{KHMDS}$ into their solutions in THF or dioxane. However, the dearomatized complexes could not be observed by NMR analysis. We thought that the problem was not deprotonation of the benzylic position of these complexes, but rather the stability of the deprotonated complexes. One way to prove this assumption was to trap the deprotonated complexes in situ. Our group has reported that dearomatized PNP pincer complexes can undergo cooperative activation of the $\mathrm{C} \equiv \mathrm{N}$ triple bonds of nitriles via [1,3]-addition to form ketimido or enamido complexes. ${ }^{29-30}$ Thus, we tried to deprotonate $\mathbf{2 a}$ in the presence of excess amount of benzonitrile. Similar to the reactions of dearomatized PNP-Re/Mn complexes, a ketimido complex 6a was formed upon addition of $\mathrm{KO}^{t} \mathrm{Bu}$ to a THF solution of $\mathbf{2 a}$ and benzonitrile at room temperature and stirring for $24 \mathrm{~h}$ (Scheme 5). A dearomatized anion intermediate $\mathbf{4} \mathbf{a}^{\prime}$ is proposed to be formed in this process. The ${ }^{31} \mathrm{P}\left\{{ }^{1} \mathrm{H}\right\}$ NMR spectrum of $\mathbf{6 a}$ exhibited a clear $\mathrm{AB}$ system at the characteristic chemical shifts of $124.27 \mathrm{ppm}$ and $83.62 \mathrm{ppm}$ with ${ }^{2} J_{\mathrm{PP}}=257.2 \mathrm{~Hz}$. In the ${ }^{1} \mathrm{H}$ NMR spectrum, the deprotonated benzylic $\mathrm{CH}$ appears as a doublet shifted to $5.61 \mathrm{ppm}\left({ }^{2} J_{\mathrm{HP}}=8.7 \mathrm{~Hz}\right)$. Moreover, the deprotonated benzylic carbon was downfield shifted to 63.20 ppm, exhibiting strong C-P coupling $\left({ }^{1} J_{\mathrm{CP}}=32.1 \mathrm{~Hz}\right)$ in the ${ }^{13} \mathrm{C}\left\{{ }^{1} \mathrm{H}\right\}$ NMR spectrum.

\section{Scheme 5. Reaction of 2a with Benzonitrile by Deprotona-} tion

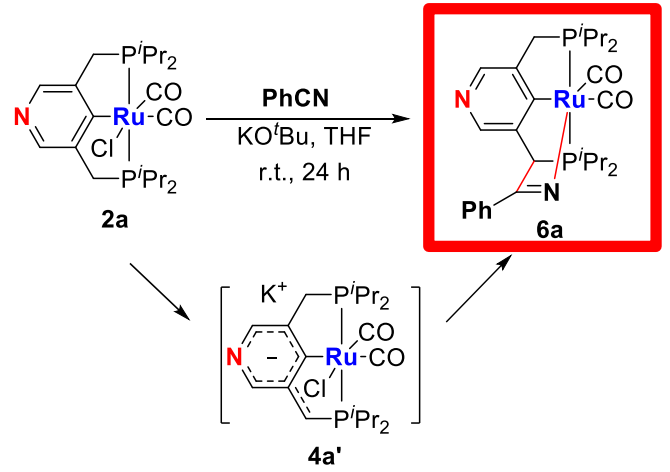

Interestingly, complex $\mathbf{6 a}$ catalyzed the Michael Addtion of benzyl nitrile to ethyl acrylate under mild conditions, in the absence of added base. Similar to the PNP pincer complexes, a nucleophilic enamido complex was pro-posed to be formed in this transformation. ${ }^{29-30}$ A mixture of single and double addition products was obtained when benzyl nitrile and ethyl acrylate was used in 1:1 ratio. Importantly, the double addition product could be isolated in quantitative yield when benzyl nitrile and ethyl acrylate were used in 1:2 ratio (eq. 1).

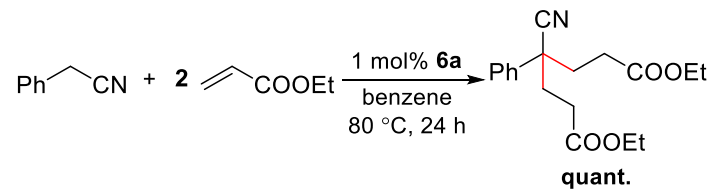

Over more than a decade, we have studied the MLC of pyridine-based PNP-Ru and PNN-Ru complexes via dearomatization/aromatization. One of the applications of this bond activation approach was the acceptorless dehydrogenative coupling reactions of alcohols to form esters. We hence explored the reaction of the pyridine-based PCP-Ru complexes with alcohols.
Addition of 10 equiv of benzyl alcohol to a benzene solution of the dearomatized 4a led to an instantaneous color change. After heating at $80{ }^{\circ} \mathrm{C}$ for $3 \mathrm{~h}, \mathbf{4 a}$ was quantitatively converted into the ruthenium hydride complex 5a (Scheme 6), and only an equivalent amount of benzaldehyde was observed by ${ }^{1} \mathrm{H}$ NMR analysis. Similar reactivity was also observed with ethanol.

\section{Scheme 6. Aromatization of 4a by Benzyl Alcohol}

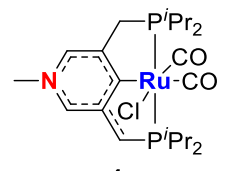

$4 a$

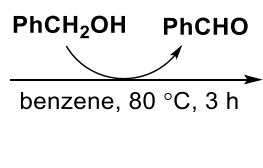

The dearomatized complex $4 \mathbf{a}(1 \mathrm{~mol} \%)$ was an efficient catalyst for the acceptorless dehydrogenative coupling of benzyl alcohol and benzylamine to form the corresponding imine in $92 \%$ NMR yield after $48 \mathrm{~h}$ in refluxing toluene (eq. 2). Hydrogen gas was detected by GC analysis.

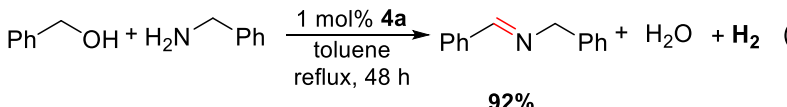

Since the dearomatized complexes expected to be formed upon deprotonation of complexes $\mathbf{2} \mathbf{a}, \mathbf{2} \mathbf{b}$ and $\mathbf{3 b}$ could not be isolated, we tried the reaction of the aromatized complexes with base and alcohol. Addition of a stoichiometric amount of $\mathrm{KO}^{t} \mathrm{Bu}$ to a THF solution of $\mathbf{2} \mathbf{a}$ and excess amount of methanol (50 equiv), the ruthenium alkoxide complex $7 \mathbf{a}$ was obtained in quantitative yields after $24 \mathrm{~h}$ at room temperature (Scheme 7). A clear shift of the ${ }^{31} \mathrm{P}$ resonance was observed by ${ }^{31} \mathrm{P}\left\{{ }^{1} \mathrm{H}\right\}$ NMR (singlet at $78.51 \mathrm{ppm}$ ). As expected, heating the THF solution of 7a led to full conversion to the ruthenium hydride complex 8a. The ${ }^{31} \mathrm{P}\left\{{ }^{1} \mathrm{H}\right\}$ NMR spectrum of 8a showed a singlet at $87.18 \mathrm{ppm}$ while the ruthenium hydride gave rise to a triplet at $-7.29 \mathrm{ppm}$ in the ${ }^{1} \mathrm{H}$ NMR spectrum. Moreover, complex 8a could also be obtained in 63\% NMR yield by the reaction between ketimido complex 6a and benzyl alcohol (50 equiv). Benzonitrile was observed by GC-MS, which indicated the reversibility of MLC of $\mathbf{4 a}^{\prime}$ with nitrile.

\section{Scheme 7. Reaction of 2a with Methanol}

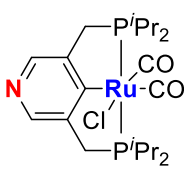

$2 a$

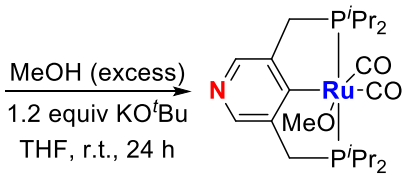

$7 a$

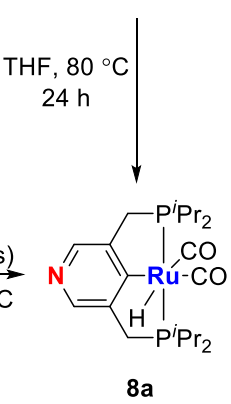


Different from the reaction of $\mathbf{2 a}$ with methanol, the ruthenium hydride complex $\mathbf{8 b}$ was directly obtained after reaction at room temperature for $24 \mathrm{~h}$ in the case of $\mathbf{2 b}$ (Scheme $8 \mathrm{a}$ ). Similarly, the reaction with $\mathbf{3} \mathbf{b}$ afforded the ruthenium hydride complex $\mathbf{5 b}$ at room temperature (Scheme 8b). The ${ }^{31} \mathrm{P}\left\{{ }^{1} \mathrm{H}\right\}$ NMR spectra of $\mathbf{8 b}$ and $\mathbf{5 b}$ showed characteristic singlets at $104.07 \mathrm{ppm}$ and $104.81 \mathrm{ppm}$, respectively. The hydride ligands appear as triplets in their ${ }^{1} \mathrm{H}$ NMR spectra at $-7.27 \mathrm{ppm}$ and 7.45 ppm, respectively. In the ${ }^{13} \mathrm{C}\left\{{ }^{1} \mathrm{H}\right\}$ NMR spectra, the ipsocarbons of $\mathbf{8 b}$ appeared at $183.41 \mathrm{ppm}$, while for $\mathbf{5 b}$ it appeared at $214.30 \mathrm{ppm}$, indicating a strong electron-withdrawing effect of the quaternized pyridine nitrogen.

\section{Scheme 8. Reactions of $\mathbf{2 b}$ and $3 \mathrm{~b}$ with Methanol}

(a)

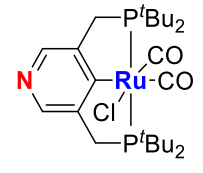

$\mathbf{2 b}$

(b)

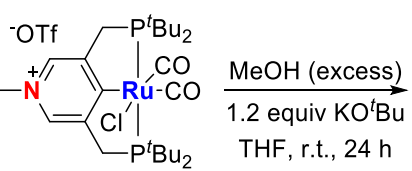

3b

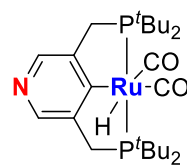

$8 b$

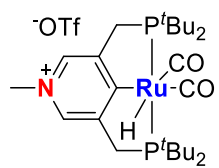

$5 b$
X-ray quality crystals of $\mathbf{8 b}$ were obtained by slowly evaporating its toluene/pentane solution, and X-ray quality crystals of $\mathbf{5 b}$ were also obtained by slowly evaporating its benzene/pentane solution (Figure 6). The ipso C-Ru bond in $\mathbf{8 b}$ is 2.116(1)
$\AA$, which is longer than that of $\mathbf{2} \mathbf{b}$. The quaternized ruthenium hydride complex $\mathbf{5 b}(2.107 \AA)$ exhibited a slightly shorter ipso $\mathrm{C}-\mathrm{Ru}$ bond than $\mathbf{8 b}$. However, the Ru-H bond of $\mathbf{5 b}(1.74(3) \AA)$ is much longer than that of $\mathbf{8 b}(1.5578 \AA)$.

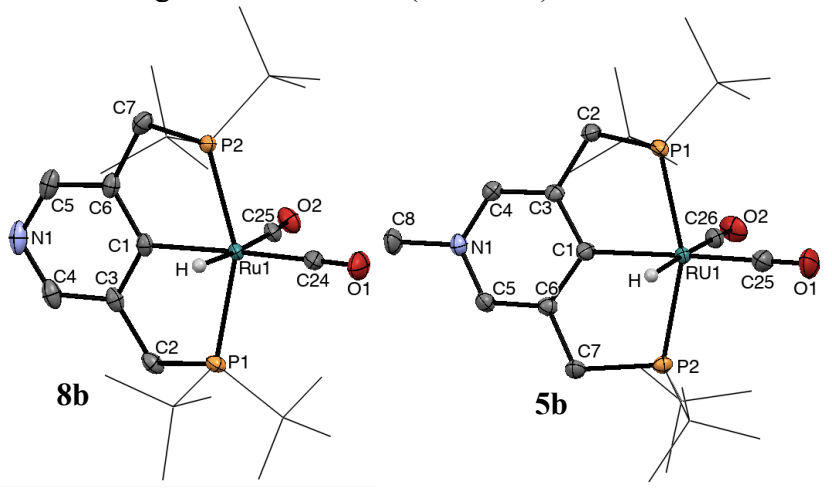

Figure 6. X-ray crystal structures of $\mathbf{8 b}$ and $\mathbf{5 b}$ (thermal ellipsoids set at $50 \%$ probability level, isopropyl and $t$-butyl groups are presented as wireframe, counter anion and hydrogen atoms except for ruthenium hydride are omitted for clarity). Selected bond distances $(\AA)$ and angles $\left({ }^{\circ}\right)$ for 8b: Ru1-C1 2.116(1), Ru1-C24 1.917(2), Ru1-C25 1.944(2), Ru1-H 1.5578, Ru1-P1 2.3556(4), Ru1-P2 2.3517(4), C6-C7 1.510(2), C2-C3 1.506(2), C1-C6 1.401(2), C1-C3 1.405(2), C3-C4 1.397(2), C5-C6 1.391(2), P1-Ru1-P2 154.59(1), C1-Ru1-H 88.9, C1-Ru1-C24 173.60(6), C24-Ru1-C25 101.95(6); 5b: Ru1-C1 2.107(2), Ru1-C25 1.923(2), Ru1-C26 1.940(3), Ru1-H 1.74(3), Ru1-P1 2.3797(5), Ru1P2 2.3635(5), C2-C3 1.503(2), C6-C7 1.506(2), C1-C3 1.410(2), C1C6 1.415(2), C3-C4 1.379(2), C5-C6 1.383(2), N1-C8 1.477(2), P1Ru1-P2 156.76(2), C1-Ru1-H 81(1), C1-Ru1-C25 164.72(9), C25Ru1-C26 98.5(1).

\section{Scheme 9. Free energy pathways for alcohol dehydrogenation} Concerted dehydrogenation pathway

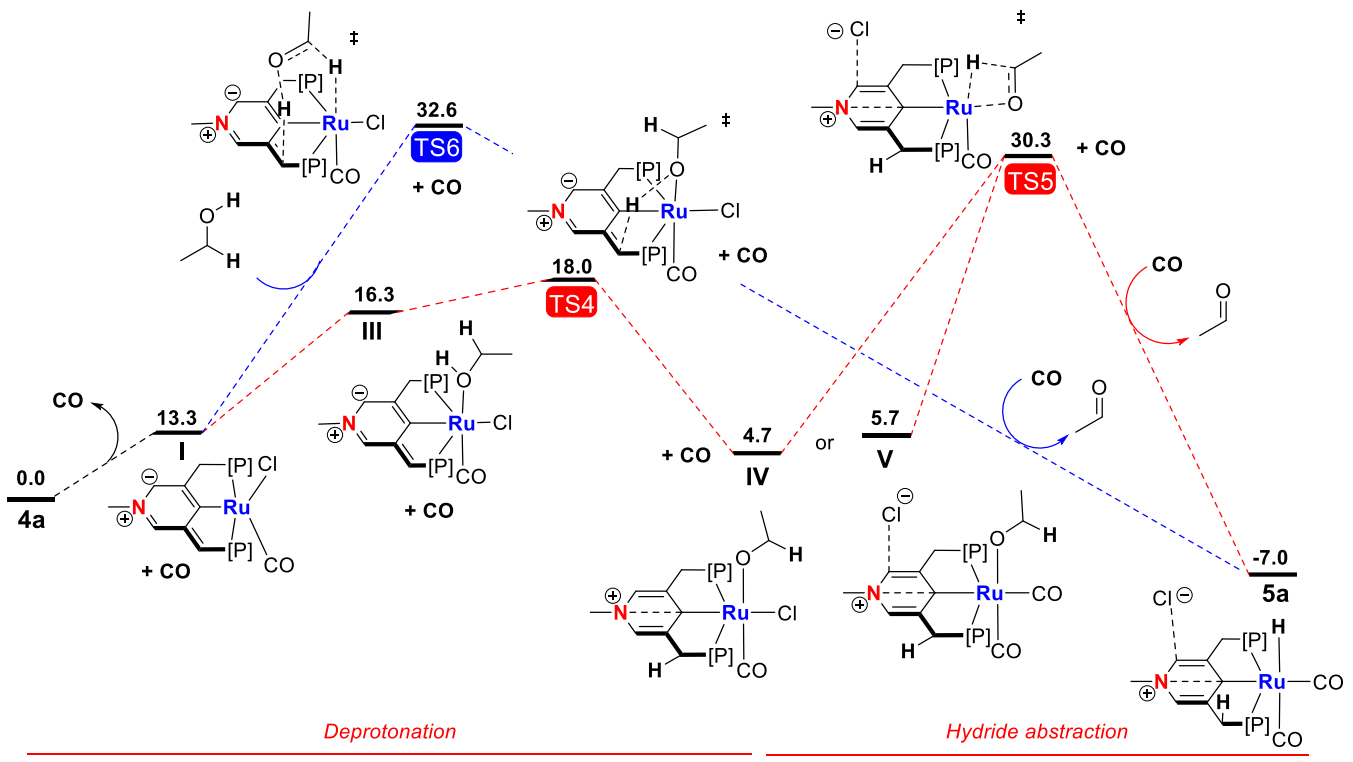

all values correspond to Gibbs free energies in $\mathrm{kcal}^{\mathrm{mol}}{ }^{-1}$ in toluene

The mechanism of alcohol dehydrogenation was also investigated by DFT calculations (Scheme 9). As for the activation of $\mathrm{H}_{2}$, a first step from 4a must be the generation of a free coordination site. Again, chloride dissociation and side-arm opening will not be treated in detail due to high activation barriers (> $37.7 \mathrm{kcal} . \mathrm{mol}^{-1}$, see SI). Deprotonation of an alcohol (ethanol) might proceed after CO-loss and alcohol addition via the deprotonation step TS4 (18.0 kcal.mol ${ }^{-1}$, Scheme 9a) to generate alkoxide species IV (4.7 $\left.\mathrm{kcalmol}^{-1}\right)$. Once the alkoxide is generate, chloride can dissociate to allow for beta-hydride elimination (TS5, $30.3 \mathrm{kcal}^{\mathrm{mol}} \mathrm{m}^{-1}$ ). Replacement of the aldehyde by CO then regenerates the hydride 5a. Slightly higher in energy is the 
concerted deprotonation/hydride abstraction pathway (TS6, $32.6 \mathrm{kcal}_{\mathrm{mol}}{ }^{-1}$, Scheme 9b), where again CO dissociation creates the open coordination site at ruthenium.

In summary, we have disclosed a new coordination mode for the MLC of pincer complexes through dearomatization/aromatization. A series of pyridine-based PCP-Ru complexes were synthesized and characterized. Interestingly, DFT calculations of quaternized pyridine-based PCP-ruthenium complexes indicate the carbenoid character of the ipso-carbon. We were able to observe the dearomatization of a quaternized pyridine-based PCP-Ru complex by direct deprotonation. NBO calculations on the dearomatized complex show the absence of carbenoid character at the ipso-position. Importantly, the dearomatized PCP$\mathrm{Ru}$ complex reacts with hydrogen or alcohols to generate the aromatized ruthenium hydride complex via MLC. This conceptually new MLC mode provides an alternative choice for the development of acceptorless dehydrogenation reactions.

\section{ASSOCIATED CONTENT}

\section{Supporting Information}

The Supporting Information is available free of charge on the ACS Publications website.

Experimental details of synthetic procedures, NMR spectra, X-ray data, and computational details (PDF)

Crystallographic data for 2a, 2b, 3a, 4a, 5b, 8b (CIF)

\section{AUTHOR INFORMATION}

\section{Corresponding Author}

*david.milstein@weizmann.ac.il

\section{Author contributions}

§Shan Tang and Niklas von Wolff contributed equally.

\section{Notes}

The authors declare no competing financial interest.

\section{ACKNOWLEDGMENT}

This research was supported by the European Research Council (ERC AdG 692775). D. M. holds the Israel Matz Professorial Chair of Organic Chemistry. S.T. is thankful to the Israel Planning and Budgeting Committee (PBC) for a postdoctoral fellowship. N.v.W. is supported by the Foreign Postdoctoral Fellowship Program of the Israel Academy of Sciences and Humanities.

\section{REFERENCES}

(1) Ikariya, T.; Blacker, A. J. Asymmetric Transfer Hydrogenation of Ketones with Bifunctional Transition Metal-Based Molecular Catalysts, Acc. Chem. Res. 2007, 40, 1300-1308.

(2) Grützmacher, H. Cooperating Ligands in Catalysis, Angew. Chem. Int. Ed. 2008, 47, 1814-1818.

(3) Khusnutdinova, J. R.; Milstein, D. Metal-Ligand Cooperation, Angew. Chem., Int. Ed. 2015, 54, 12236-12273.

(4) Morales-Morales, D.; Jensen, C. M. The chemistry of pincer compounds; 1st ed.; Elsevier: Amsterdam ; Boston, 2007.

(5) Koten, G. v.; Milstein, D. Organometallic pincer chemistry; Springer: Berlin ; New York, 2013.

(6) van der Boom, M. E.; Milstein, D. Cyclometalated PhosphineBased Pincer Complexes: Mechanistic Insight in Catalysis, Coordination, and Bond Activation, Chem. Rev. 2003, 103, 17591792.

(7) Selander, N.; Szabó, K. J. Catalysis by Palladium Pincer Complexes, Chem. Rev. 2011, 111, 2048-2076.
(8) Kumar, A.; Bhatti, T. M.; Goldman, A. S. Dehydrogenation of Alkanes and Aliphatic Groups by Pincer-Ligated Metal Complexes, Chem. Rev. 2017, 117, 12357-12384.

(9) Benito-Garagorri, D.; Kirchner, K. Modularly Designed Transition Metal PNP and PCP Pincer Complexes based on Aminophosphines: Synthesis and Catalytic Applications, Acc. Chem. Res. 2008, 41, 201-213.

(10) Gunanathan, C.; Milstein, D. Metal-Ligand Cooperation by Aromatization-Dearomatization: A New Paradigm in Bond Activation and "Green" Catalysis, Acc. Chem. Res. 2011, 44, 588602.

(11) Zhang, J.; Leitus, G.; Ben-David, Y.; Milstein, D. Facile Conversion of Alcohols into Esters and Dihydrogen Catalyzed by New Ruthenium Complexes, J. Am. Chem. Soc. 2005, 127, 1084010841.

(12) Ben-Ari, E.; Leitus, G.; Shimon, L. J. W.; Milstein, D. MetalLigand Cooperation in $\mathrm{C}-\mathrm{H}$ and $\mathrm{H} 2$ Activation by an ElectronRich PNP $\operatorname{Ir}(\mathrm{I})$ System: Facile Ligand DearomatizationAromatization as Key Steps, J. Am. Chem. Soc. 2006, 128, 1539015391.

(13) Zhang, J.; Leitus, G.; Ben-David, Y.; Milstein, D. Efficient homogeneous catalytic hydrogenation of esters to alcohols, Angew. Chem., Int. Ed. 2006, 45, 1113-1115.

(14) Gunanathan, C.; Milstein, D. Applications of Acceptorless Dehydrogenation and Related Transformations in Chemical Synthesis, Science 2013, 341, 249.

(15) Gunanathan, C.; Milstein, D. Bond Activation and Catalysis by Ruthenium Pincer Complexes, Chem. Rev. 2014, 114, 1202412087.

(16) Prokopchuk, D. E.; Tsui, B. T. H.; Lough, A. J.; Morris, R. H. Intramolecular C-H/O-H Bond Cleavage with Water and Alcohol Using a Phosphine-Free Ruthenium Carbene NCN Pincer Complex, Chem. Eur. J. 2014, 20, 16960-16968.

(17) Sun, Y.; Koehler, C.; Tan, R.; Annibale, V. T.; Song, D. Ester hydrogenation catalyzed by Ru-CNN pincer complexes, Chem. Commun. 2011, 47, 8349-8351.

(18) Fogler, E.; Garg, J. A.; Hu, P.; Leitus, G.; Shimon, L. J. W.; Milstein, D. System with Potential Dual Modes of Metal-Ligand Cooperation: Highly Catalytically Active Pyridine-Based PNNHRu Pincer Complexes, Chem. Eur. J. 2014, 20, 15727-15731.

(19) Filonenko, G. A.; Cosimi, E.; Lefort, L.; Conley, M. P.; Copéret, C.; Lutz, M.; Hensen, E. J. M.; Pidko, E. A. Lutidine-Derived RuCNC Hydrogenation Pincer Catalysts with Versatile Coordination Properties, ACS Catal. 2014, 4, 2667-2671.

(20) Balaraman, E.; Gnanaprakasam, B.; Shimon, L. J. W.; Milstein, D. Direct Hydrogenation of Amides to Alcohols and Amines under Mild Conditions, J. Am. Chem. Soc. 2010, 132, 1675616758.

(21) Li, H.; Zheng, B.; Huang, K.-W. A new class of PN3-pincer ligands for metal-ligand cooperative catalysis, Coordin. Chem. Rev. 2015, 293-294, 116-138.

(22) Ashkenazi, N.; Vigalok, A.; Parthiban, S.; Ben-David, Y.; Shimon, L. J. W.; Martin, J. M. L.; Milstein, D. Discovery of the First Metallaquinone, J. Am. Chem. Soc. 2000, 122, 8797-8798.

(23) Dauth, A.; Gellrich, U.; Diskin-Posner, Y.; Ben-David, Y.; Milstein, D. The Ferraquinone-Ferrahydroquinone Couple: Combining Quinonic and Metal-Based Reactivity, J. Am. Chem. Soc. 2017, 139, 2799-2807.

(24) Kosanovich, A. J.; Komatsu, C. H.; Bhuvanesh, N.; Pérez, L. M.; Ozerov, O. V. Dearomatization of the PCP Pincer Ligand in a ReV Oxo Complex, Chem. Eur. J. 2018, 24, 13754-13757.

(25) Bordwell, F. G. Equilibrium acidities in dimethyl sulfoxide solution, Acc. Chem. Res. 1988, 21, 456-463.

(26) Weisman, A.; Gozin, M.; Kraatz, H.-B.; Milstein, D. Rhodium and Palladium Complexes of a 3,5-Lutidine-Based Phosphine Ligand, Inorg. Chem. 1996, 35, 1792-1797.

(27) van der Boom, M. E.; Iron, M. A.; Atasoylu, O.; Shimon, L. J. W.; Rozenberg, H.; Ben-David, Y.; Konstantinovski, L.; Martin, J. M L.; Milstein, D. sp3 $\mathrm{C}-\mathrm{H}$ and $\mathrm{sp} 2 \mathrm{C}-\mathrm{H}$ agostic ruthenium complexes: a combined experimental and theoretical study, Inorg. Chim. Acta 2004, 357, 1854-1864. 
(28) Stander-Grobler, E.; Schuster, O.; Heydenrych, G.; Cronje, S.; Tosh, E.; Albrecht, M.; Frenking, G.; Raubenheimer, H. G. Pyridine-Derived N-Heterocyclic Carbenes: An Experimental and Theoretical Evaluation of the Bonding in and Reactivity of Selected Normal and Abnormal Complexes of Nickel(II) and Palladium(II), Organometallics 2010, 29, 5821-5833.

(29) Nerush, A.; Vogt, M.; Gellrich, U.; Leitus, G.; Ben-David, Y.; Milstein, D. Template Catalysis by Metal-Ligand Cooperation. C$\mathrm{C}$ Bond Formation via Conjugate Addition of Non-activated Nitriles under Mild, Base-free Conditions Catalyzed by a Manganese Pincer Complex, J. Am. Chem. Soc. 2016, 138, 69856997.
(30) Vogt, M.; Nerush, A.; Iron, M. A.; Leitus, G.; Diskin-Posner, Y.; Shimon, L. J. W.; Ben-David, Y.; Milstein, D. Activation of Nitriles by Metal Ligand Cooperation. Reversible Formation of Ketimido- and Enamido-Rhenium PNP Pincer Complexes and Relevance to Catalytic Design, J. Am. Chem. Soc. 2013, 135, 17004-17018. 


dearomatization

